\title{
Assistentes Sociais na vanguarda da pandemia da COVID-19: tensionamentos e resistências
}

\author{
Ana Paula Cardoso da Silva* \\ Luciane Barbosa do Amaral Rangel**
}

Social workers at the forefront of the COVID-19 pandemic: tension and resistance

\begin{abstract}
Resumo - O presente texto se propõe precipuamente a homenagear aos/às Assistentes Sociais que estão na linha de frente de atuação nas diversas políticas públicas no cenário de crise estrutural do capital, acentuado com os limites e os desafios trazidos diante da conjuntura pandêmica do novo coronavírus, em especial, às profissionais que perderam a vida neste período no exercício de suas funções. Serão abordados alguns tensionamentos e estratégias de resistência enfrentados nos cotidianos dos espaços sócio-ocupacionais, sobretudo, nas políticas de Saúde e de Assistência Social.

Palavras-chave: Exercício Profissional; Resistência; Pandemia; Políticas Públicas.
\end{abstract}

\begin{abstract}
This text is primarily intended to pay homage to Social Workers who are at the forefront of action in the various public policies in the scenario of structural crisis of capital, accentuated with the limits and challenges brought about by the pandemic conjuncture of the new coronavirus, especially to professionals who lost their lives in this period in the exercise of their functions. Some tension and resistance strategies faced in the daily lives of socio-occupational spaces will be addressed, especially in the policies of Health and Social Assistance.
\end{abstract}

Keywords: Professional Practice; Resistance; Pandemic; Public Policies.

\footnotetext{
* Mestre em Serviço Social pelo Programa de Pós-Graduação em Serviço Social e Desenvolvimento Regional (PPGSSDR) da UFF - Especialista em Assistência Social e Direitos Humanos pela Pontifícia Universidade Católica do Rio de Janeiro (PUC-Rio) - Assistente Social do Hospital Federal dos Servidores do Estado (HFSE) e da Secretaria Municipal de Assistência Social e Direitos Humanos do Rio de Janeiro (SMASDH/RJ) - Conselheira Vice-Presidenta do Conselho Regional de Serviço Social do Rio de Janeiro (CRESS/RJ) da Gestão 2020-2023. E-mail: as.anapaula @gmail.com. ORCID: https://orcid.org/0000-0003-0634-5512.

** Mestranda em Serviço Social pelo Programa de Pós-Graduação em Serviço Social da PUC-Rio - Especialista em Assistência Social e Direitos Humanos pela PUC-Rio - Assistente Social da Secretaria Municipal de Assistência Social e Direitos Humanos (SMASDH/RJ) - Conselheira Presidenta do Conselho Regional de Serviço Social do Rio de Janeiro (CRESS/RJ) da Gestão 2020-2023. E-mail: lu.amaralrangel@gmail.com. ORCID: https://orcid.org/0000-0002-92225279.
} 


\section{Introdução} "A gente sabe que a gente está ativa, está militando,
está resistindo o tempo todo."

Marielle Franco

Primeiramente, é essencial pontuar que a pandemia do novo coronavírus está corroborando para descortinar a profunda e histórica desigualdade social brasileira, provando a duros golpes à sociedade civil e ao Estado, nos âmbitos federal, estaduais e municipais que sem políticas públicas, mesmo que extremamente sucateadas e fragilizadas, sobretudo, o Sistema Único de Saúde (SUS) e o Sistema Único de Assistência Social (SUAS), os impactos negativos poderiam ser ainda maiores no atual contexto. E os/as Assistentes Sociais seguem atuando nos diversos espaços sócio-ocupacionais (saúde, assistência social, sociojurídico, educação, previdência social, entre outros) presencialmente e/ou remotamente, tendo seu processo de trabalho complexificado na pandemia em curso, resistindo cotidianamente com a população usuária. De fato, é preciso ter muita coragem, compromisso, planejamento e coletividade para prosseguir!

Isto posto, vale frisar ser uma enorme satisfação participar desta Homenagem de vida da Edição n. 48 da Revista em Pauta da Universidade Estadual do Rio de Janeiro (UERJ), onde os/as protagonistas merecidamente são os/as Assistentes Sociais que estão atuando na "linha de frente" da pandemia da COVID-19.

\section{Tensionamentos e resistências no exercício profissional na pandemia do novo coronavírus}

Vive-se os efeitos da crise sistêmica do capital hipertrofiada pela crise sanitária, em um contexto de um desgoverno ultraneoliberal, genocida, racista, misógino e homofóbico, o qual prioriza lucros e não vidas, baseado no darwinismo social, na criminalização da questão social, no desmonte das já desmanteladas políticas sociais e na perda aviltante de direitos. Cabe salientar aqui, que apesar destas políticas não serem o fim da luta cotidiana nos heterogêneos espaços sócio-ocupacionais que o Serviço Social atua, essas são caminhos cruciais e profícuos de reprodução e resistência da classe trabalhadora, sem perder o norte da busca por uma nova sociabilidade.

Até porque, dentro de um contexto de capitalismo selvagem, a "revolução dentro da ordem" (aquela que é proposta dentro da ordem capitalista para mantê-la) é contida pelo capital, "é bloqueada pelas classes possuidoras e privilegiadas, porque as massas despossuídas estão tentando aprender como realizar a revolução contra a ordem" (FERNANDES, 1981, p. 42). 
Sendo assim, sabe-se que a burguesia se utiliza do Estado para atingir o seu fim. Analisando sob este prisma, as políticas públicas exemplificam bem este propósito, mas também, expressam resultados da luta da classe trabalhadora, pode-se assim, tê-las como exemplos de ações da "revolução dentro da ordem", na ótica do trabalho, como vias para a construção da "revolução contra a ordem" e simultaneamente, na ótica do capital, indicam a "revolução dentro da ordem", visto que não indicam rupturas com a ordem vigente e objetivam reproduzir e legitimar a ordem burguesa.

Já ações que almejam a "revolução contra a ordem", ou seja, com fins de rupturas com o atual status quo para a construção de uma nova ordem societária são muito mais complexas e difíceis de serem equacionadas, exigindo um esforço coletivo de lutas mais consistentes e contínuas, visto que só se efetivará por meio de uma "[...] rebelião popular e radical, de orientação socialista [...] para a realização dos padrões mais elevados da razão humana" (ibidem, p. 32).

Considerando o exposto, consta no artigo 3, inciso d, do Código de Ética do/a Assistente Social: "participar de programas de socorro à população em situação de calamidade pública, no atendimento e defesa de seus interesses e necessidades" (CFESS, 2012). Mas, em que condições objetivas e subjetivas se dão tal participação? Sabe-se que muitos/as profissionais que estão atuando presencialmente na linha de frente do atendimento durante a pandemia do novo coronavírus não têm os equipamentos de proteção individuais (EPI's) e coletivos (EPC's) satisfatórios para uma atuação segura e protegida. Sabe-se ainda que o discurso de que "estamos todos no mesmo barco" corroborou com o reforço às tendências de desprofissionalização e desespecialização, além dos desafios enfrentados para a garantia do sigilo e a intensificação, mesmo que com novas roupagens, das requisições indevidas no exercício profissional, especialmente, nas políticas de Assistência Social e de Saúde.

É essencial pontuar que: "nenhum profissional tem que ter o perfil da política, mas o perfil que corresponda ao projeto da sua profissão" (GUERRA, 2019, p. 120), a fim de que não confunda os objetivos da política pública e institucionais com os objetivos profissionais, estes pautados ética e politicamente na defesa intransigente dos direitos humanos.

Faz-se assim, indispensável destacar as competências profissionais e as atribuições privativas, previstas na Lei de Regulamentação da Profissão (n. 8.662/93). Cabe frisar aqui, que para Florestan Fernandes (1981) o trabalho intelectual não pode estar desvinculado da ação política, daí o papel do "intelectual militante", que a partir do diálogo com o marxismo, constrói o embasamento teórico-metodológico, tendo como horizonte de análise e de luta política a construção de uma nova ordem societária. Para o autor, somente tomando por base a centralidade nas relações de classe, através do conhecimento da dominação burguesa será possível contribuir com a transformação da sociedade capitalista. 


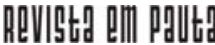

\} ASSISTENTES SOCIAIS NA VANGUARDA - SILVA, A. P. C.; RANGEL, L. B. A. \}

DOI: $10.12957 /$ REP.2021.60312

Na sociedade burguesa, difundi-se um discurso da igualdade para a manutenção da desigualdade, intrínseca ao sistema capitalista, assim, é incongruente falar em cidadania neste modo de produção, onde a política social não necessariamente a possibilita. Todavia, a luta de classes é imprescindível para a conquista de direitos e melhorias das condições de vida da classe trabalhadora, "(...) contribuindo para a construção de uma sociedade onde o homem - e não a mercadoria - seja o princípio orientador de construção da sociedade" (MARTINS, 2012, p. 86), haja vista que as políticas sociais não são pensadas para enfrentar a pobreza e a desigualdade, tampouco erradicá-las, porém, para geri-las, minimizar seus efeitos e neutralizar conflitos sociais.

A atual conjuntura é propícia ao fatalismo profissional, na qual por vezes faltam forças para permanecer lutando e resistindo. Tem-se o medo natural da morte pela COVID-19, da contaminação pelo novo coronavírus, o medo de perder o emprego, o medo de ser perseguido/a no ambiente de trabalho por tensionar e se posicionar no cotidiano, o incômodo assédio moral em alguns casos, o extremo abalo emocional que este cenário afeta a todos/as. Por outro lado, não se deve ir ao extremo, que é o messianismo, visto que somos mulheres, em sua grande maioria, e homens que necessitam de condições seguras e éticas para o exercício do seu trabalho, e precisamos nos manter vivos/as para tal. Qual seria a saída então? A retórica é: a saída é coletiva! Não há outra. Faz-se necessário o espraiamento da participação da categoria no Conselho Profissional ${ }^{1}$, em sindicatos que coadunam com as Bandeiras de Luta ${ }^{2}$ do Serviço Social e em espaços de controle social das políticas públicas e de articulação coletiva dos/as trabalhadores/ as, a exemplo dos Fóruns. Neste cenário é de extrema relevância, o planejamento das ações e a sistematização cotidiana da prática como elementos estratégicos de resistência profissional. Em suma, momentos de suspensão do cotidiano são vitais na contemporaneidade.

\section{Considerações Finais}

O cenário contemporâneo é ultradesafiador para a classe trabaIhadora, sendo o Serviço Social também afetado evidentemente por estar inserido na divisão social e técnica do trabalho. Todavia, como qualquer contexto histórico, este é permeado por lutas, contradições e possibilidades. Dessa forma, é imprescindível a intensificação da capacitação continuada para a atuação profissional no período pós-pandemia, onde as facetas da questão social estarão ainda mais graves e complexas.

\footnotetext{
'A saber, o Conselho Regional de Serviço Social (CRESS) é regulamentado pela lei 8.662/1993 e se constitui como autarquia com personalidade jurídica de direito público vinculada ao Conselho Federal de Serviço Social (CFESS). O CRESS tem como funções, dentre outras, a orientação e fiscalização do exercício profissional de assistentes sociais. ${ }^{2}$ Vide documento Bandeiras de Luta do Conjunto CFESS/CRESS (2018).
} 


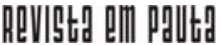

\} ASSISTENTES SOCIAIS NA VANGUARDA - SILVA, A. P. C.; RANGEL, L. B. A. \}

DOI: $10.12957 /$ REP.2021.60312

Diante do exposto, é fundamental a defesadas bandeiras de luta do Conjunto CFESS-CRESS, dentre as quais, permanecer lutando pela revogação da Emenda Constitucional (EC) 95/2016, referente ao teto dos gastos públicos por 20 anos e ressaltar especialmente, a valorização do SUAS e do SUS, com ênfase no Princípio Fundamental II do Código de Ética Profissional: "defesa intransigente dos direitos humanos e recusa do arbítrio e do autoritarismo." (BRASIL, 2012).

Enfim, cabe destacar a relevância da articulação das dimensões teórico-metodológico, técnico-operativo e ético-político do fazer profissional. Assim, principalmente, neste contexto desafiador, destaque também ao princípio fundamental do Código de Ética Profissional de Assistentes Sociais (ibidem): $X$ - o compromisso com a qualidade dos serviços prestados à população e com o aprimoramento intelectual, na perspectiva da competência profissional.

Em suma, aos/às profissionais aguerridas/os que se reinventam nos cotidianos dos espaços profissionais com parcos recursos e exaustivas jornadas de trabalho, seja presencialmente e/ou remotamente, em prol da efetivação de direitos das usuários/as dos serviços, a nossa admiração e respeito! Vocês são símbolos de inspiração e resistência da história da nossa categoria em tempos tão adversos, e merecem total valorização e condições condignas de trabalho na busca incessante pela efetivação desses direitos. 


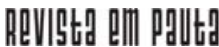

ISSISTENTES SOCIAIS NA VANGUARDA - SILVA, A. P. C.; RANGEL, L. B. A. \}

DOI: 10.12957/REP.2021.60312

\section{Referências}

BRASIL. Bandeiras de Luta do Conjunto CFESS/CRESS. Brasília: Conselho Federal de Serviço Social, 2018.

BRASIL. Código de ética do/a assistente social. Lei 8.662/93 de regulamentação da profissão. 10a . ed. rev. e atual. - Brasília: Conselho Federal de Serviço Social, 2012.

FERNANDES, F. Capitalismo Dependente e Classes Sociais na América Latina. 3. ed. Rio de Janeiro: Zahar, 1981.

GUERRA, Y. Desafios para o Serviço Social na Seguridade Social: Formação nas Políticas ou Para as Políticas Sociais? In: GUERRA, Yolanda, LEITE, Janete Luzia e ORTIZ, Fátima Grave (orgs.). Temas contemporâneos em Serviço Social: uma análise de seus fundamentos. Campinas: Papel Social, 2019.

MARTINS, A. de C. Risco social: terminologia adequada para a proteção social e garantia dos direitos? Em Pauta, Rio de Janeiro, 1ํㅡㄹ semestre de 2012, n. 29, v.10, p. 85-99.

DOI: $10.12957 /$ rep.2021.60312

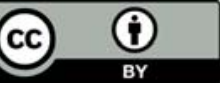

A Revista Em Pauta: Teoria Social e Realidade Contemporânea está licenciada com uma Licença Creative Commons Atribuição 4.0 Internacional. 